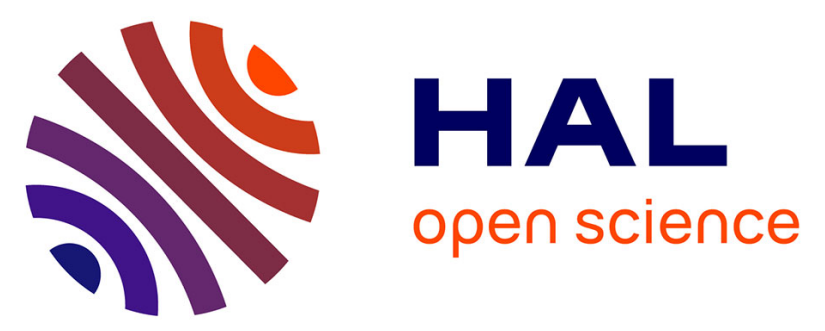

\title{
LOW ENERGY, HIGH-FLUX NITRIDATION OF FACE CENTRED CUBIC METALLIC MATRICES
}

Fernando Pedraza, C. Savall, G. Abrasonis, J.P Rivière, J.F Dinhut, Jean-Luc Grosseau-Poussard

\section{- To cite this version:}

Fernando Pedraza, C. Savall, G. Abrasonis, J.P Rivière, J.F Dinhut, et al.. LOW ENERGY, HIGHFLUX NITRIDATION OF FACE CENTRED CUBIC METALLIC MATRICES. Thin Solid Films, 2007, 515, pp.3661-3669. 10.1016/j.tsf.2006.10.081 . hal-00512802

\section{HAL Id: hal-00512802 https://hal.science/hal-00512802}

Submitted on 1 Sep 2010

HAL is a multi-disciplinary open access archive for the deposit and dissemination of scientific research documents, whether they are published or not. The documents may come from teaching and research institutions in France or abroad, or from public or private research centers.
L'archive ouverte pluridisciplinaire HAL, est destinée au dépôt et à la diffusion de documents scientifiques de niveau recherche, publiés ou non, émanant des établissements d'enseignement et de recherche français ou étrangers, des laboratoires publics ou privés. 


\section{LOW ENERGY, HIGH-FLUX NITRIDATION OF FACE CENTRED CUBIC METALLIC MATRICES}

F. Pedraza $^{1 *}$, C. Savall ${ }^{1}$, G. Abrasonis ${ }^{2 * *}$, J.P. Rivière ${ }^{2}$, J.F. Dinhut ${ }^{1}$, J.L. GrosseauPoussard $^{1}$

1 Laboratoire d'Etudes des Matériaux en Milieux Agressifs (LEMMA, EA3167). Université de La Rochelle. Pôle Sciences et Technologie. Bâtiment Marie Curie. Avenue Michel Crépeau. 17042 La Rochelle cedex 1. FRANCE.

2 Laboratoire de Métallurgie Physique, UMR 6630 CNRS, Université de Poitiers. Bâtiment SP2MI. Boulevard Marie et Pierre Curie. BP 30179. Futuroscope-Chasseneuil cedex. France.

* corresponding author: F. Pedraza, Tel :+33(0)5.46.45.82.97, Fax :+33(0).5.46.45.72.72, e-mail : fpedraza@univ-lr.fr

** present address: Institute of Ion Beam Physics and Materials Research, Forschungszentrum Rossendorf, PO Box 5101 19. D-01314 Dresden, GERMANY. 


\begin{abstract}
In this work, a comparative study on the effects of a low energy, high-flux nitrogen implantation at moderate temperature on different fcc metallic matrices ( $\mathrm{Ni}, \mathrm{NiCr}_{20}$ and $\mathrm{FeCr}_{20} \mathrm{Ni}_{10}$ ) is presented. The nitrided layer main features (thickness, composition and surface roughness) will be shown to be markedly dependant on the original substrate composition. As calculated by thermodynamic analyses, the low chemical affinity of pure nickel towards nitrogen accounts for ineffective nitridation, whereas the presence of chromium clearly promotes nitrogen diffusion into the matrix. Comparatively, $N$ uptake is enhanced in the Fe-rich matrix thus suggesting a beneficial role of iron. As a result, a expanded austenite layer is formed in both Cr-containing substrates which brings about a significant increase in microhardness. Roughening of the nickel surfaces mainly occurs by sputtering whereas nitrogen-induced deformation seems to be the main responsible in the $\mathrm{NiCr}_{20}$ and $\mathrm{FeCr}_{20} \mathrm{Ni}_{10}$ substrates.
\end{abstract}

Keywords: nitrogen implantation, fcc metal matrix, expanded austenite, hardening. 


\section{1.- Introduction}

Nitridation treatments by low energy, high-flux implantation at moderate temperatures $\left(\sim 400^{\circ} \mathrm{C}\right.$ ) have been reported to produce relatively thick nitrided layers enhancing all together tribological [1-5] and corrosion resistance [6] in face-centred-cubic (fcc) stainless steels as a result of the formation of a fcc $\gamma_{\mathrm{N}}$ phase (expanded austenite) so long as precipitation of $\mathrm{CrN}$ is avoided [7]. Few studies are however devoted to the implantation-diffusion of nitrogen into other metallic matrices. Williamson et al. [8] focused on the study of 16 fcc Fe and Ni-based alloys and already claimed that higher nitrogen solubilities were obtained in the iron-rich materials compared to the nickel-rich alloys and that higher contents of alloying elements were also responsible of enhanced nitrogen incorporation, especially chromium. In addition, the comparative study of the tribological behaviour of a low energy, high-flux nitrided stainless steel and a nickel base alloy (Inconel 600) also showed better resistance of the Fe-rich substrate than the Ni-based alloy because of a thinner nitrided layer developed in the latter [9].

Therefore, in this work it is intended to compare the effects of a low energy high flux nitridation process on three face centred cubic (fcc) metallic structures, namely pure nickel (Ni), a nichrome $\left(\mathrm{NiCr}_{20}\right)$ and an AISI 304L stainless steel $\left(\mathrm{FeCr}_{20} \mathrm{Ni}_{10}\right)$.

\section{2.- Experimental procedure}

All the samples were mechanically polished to $1 \mu \mathrm{m}$ diamond paste (average roughness, $\mathrm{R}_{\mathrm{a}}=0.01 \mu \mathrm{m}$ ) , then ultrasonically degreased in acetone and subsequently rinsed in $96 \%$ ethanol. The major composition and implantation temperature of the fcc materials under investigation are given in Table 1 . Prior to nitridation, all the samples were subjected to Ar sputtering (1.2 keV, $0.5 \mathrm{~mA} . \mathrm{cm}^{-2}$ for 10 minutes) to remove the naturally forming oxide film that may prevent nitridation [10].

Nitrogen implantation was performed with a Kaufman-type ion source $7.5 \mathrm{~cm}$ diameter delivering 55\% $\mathrm{N}_{2}{ }^{+}$and $45 \% \mathrm{~N}^{+}$[5], which were accelerated at low energy (1.2 keV), high-flux $\left(1 \mathrm{~mA} . \mathrm{cm}^{-2}\right)$ for 1 hour to obtain similar doses of $2.25 \times 10^{19} \mathrm{~cm}^{-2}$. The initial vacuum in the chamber is $10^{-4} \mathrm{~Pa}$ and raises to $10^{-2} \mathrm{~Pa}$ during implantation. The temperature of the samples was carefully controlled with a thermocouple attached to the 
back of the samples. Because of the different nitrogen-alloy interactions for similar nitridation conditions, the maximum substrate temperatures values also differed (see Table 1) but never surpassed $500^{\circ} \mathrm{C}$.

Thermodynamic calculations have been performed using the HSC Chemistry software [11] to assess the thermodynamically stable compounds expected to form within the different matrices. The calculations have been carried out at equilibrium conditions at $10^{-2} \mathrm{~Pa}$ (implantation conditions) and at atmospheric pressure (after implantation) disregarding collision cascades and sputtering of the surfaces. Only the gas species $\mathrm{N}_{2}{ }^{+}$ (g) or $\mathrm{N}_{2}$ (g) have been considered to react with the substrates, thus taking into account the splitting of the molecules into 2 nitrogen atoms and the corresponding energy release.

After nitridation, the samples were characterised using contact mode atomic force microscopy (AFM) with an Autoprobe CPR (Veeco Instruments), X-ray diffraction (XRD) in the Bragg-Brentano configuration of a Bruker AXS D-5005 equipment using a copper anode $\left(\mathrm{Cu} \mathrm{K} \mathrm{K}_{\alpha 1}=0.15406 \mathrm{~nm}\right)$ and scanning electron microscopy (SEM) coupled to energy-dispersive spectrometry (EDS) in a JEOL JSM-5410LV. Acquisition of the microhardness values at different depths of the nitrided and non nitrided specimens has been carried in a Shimadzu Type $\mathrm{M}$ microhardness tester by increasing the applied load. 10 indentations have been carried out for each load to better average the actual microhardness values.

\section{3.- Results}

\section{1.- Characterisation of nitrided specimens}

The XRD comparative diffractograms are shown in Figure 1. It can be readily observed that in nitrided Ni no additional peaks appear compared to the pattern of the untreated metal. Calculation of the lattice parameters of both untreated and nitrided substrates leads to similar results $\left(\mathrm{a}_{0} \approx 0.351 \mathrm{~nm}\right)$, which confirms that no expansion of the fcc lattice has occurred by nitrogen solid solution in nickel. 
Conversely, after nitridation, the Cr-bearing alloys develop satellite peaks at lower diffraction angles than the initial $\gamma$ phase indicating the formation of the expanded austenite $\gamma_{\mathrm{N}}$ but no metal nitrides [Figures 1(b) and 1(c)]. X-ray absorption by Ni atoms is known to be weaker than for Fe atoms thus further penetration of the X-rays may occur in the $\mathrm{NiCr}_{20}$ matrix than in $\mathrm{FeCr}_{20} \mathrm{Ni}_{10}$. Therefore, in order to better compare the differences between both implanted chromium-containing substrates a rough estimation of the retained nitrogen has been carried out as reported by Williamson et al. [8] in which a linear correlation between lattice parameter and atomic concentration was employed using Vegard's law for substitutional solid solution as follows: $a_{\gamma N}=a_{\gamma}+\alpha \cdot C_{N}$, where $\mathrm{a}_{\gamma \mathrm{N}}$ and $\mathrm{a}_{\gamma}$ are the lattice parameters for the $\mathrm{N}$-containing and $\mathrm{N}$-free $\gamma$ phases, respectively, and $\alpha$ is the Vegard's law constant (0.00072 for Fe alloys, also assumed for $\mathrm{Ni}$ alloys in this study [8]). $\mathrm{C}_{\mathrm{N}}$ is the concentration of nitrogen in atomic \%. The results of these calculations are presented in Table 2.

From the results of Table 2, it can be observed that the retained amount of nitrogen in $\mathrm{NiCr}_{20}$ is significantly lower than in $\mathrm{FeCr}_{20} \mathrm{Ni}_{10}$ regardless of the crystallographic plane. In both substrates however, it would seem that the highest amount of nitrogen concentrates in the (200) planes and the lowest in the (220). The different partitioning of nitrogen in the various planes also brings about different expansion of the lattice, which in turn may induce strains and stresses as will be discussed later.

Figure 2 shows the negative images of the SEM surface morphologies of the different metallic substrates after implantation, hence the lightest areas are deeper and the darkest are higher in real conditions. In pure Ni some grains are dark and the orientation of the dislocation slipping bands composing each grain is underpinned; while other grains are lighter in colour and of smoother appearance. In addition, a significant number of protrusions appear throughout the entire surface, especially at the grain boundaries. In $\mathrm{NiCr}_{20}$ the surface is rather uniform and smooth with no protrusions but with relatively coarse pores. The $\mathrm{FeCr}_{20} \mathrm{Ni}_{10}$ surface is the most heterogeneous of all three fcc nitrided substrates. As in pure $\mathrm{Ni}$, some of the grains exhibit aligned dislocation slipping bands, whereas other are relatively smooth and remind those of $\mathrm{NiCr}_{20}$. As opposed to pure $\mathrm{Ni}$ and $\mathrm{NiCr}_{20}$ neither protrusions nor porosity are observed though. 
According to EDS microanalyses no nitrogen has been retained in pure Ni either within the grains or at the grain boundaries where more protrusions are observed. However, this can also be due to the poor detection limit of light elements by the EDS technique. Conversely, different nitrogen contents are found in both chromium-bearing alloys. For instance, in $\mathrm{NiCr}_{20}$ about 10 at\% $\mathrm{N}$ is present at the surface regardless of the location whereas in $\mathrm{FeCr}_{20} \mathrm{Ni}_{10}$ some of the grains only incorporate about 12 at\% $\mathrm{N}$ whereas some others contain up to 17 at\% $\mathrm{N}$, which is close to the chromium content in the substrate. In order to provide further insight on this issue, AFM investigations have therefore been carried out.

Figure 3 compiles some characteristic 3D AFM images of the three substrates after nitridation and their associated height profiles. The nitrided pure Ni shows a very uneven and grainy surface with roughness values (from $10 \times 10 \mu \mathrm{m}^{2}$ images) that range between 175 and $275 \AA$. Some of the grains exhibit the aligned bands also observed by SEM (see Fig. 2) and can be ascribed to the slipping bands due to the presence of stress, as also reported in fcc AISI 316 L stainless steel [12]. From the height profile of Ni, it can be observed that the average height is of about $0.3 \mu \mathrm{m}$ except for the white grain in the centre of the AFM image. In nitrided $\mathrm{NiCr}_{20}$ however, the surfaces are rather smooth within the grains (average roughness from $10 \times 10 \mu \mathrm{m}^{2}$ images, $\mathrm{R}_{\mathrm{a}}=50-80 \AA \AA$ ) but more significant height differences among grains compared to nitrided Ni. In addition, some of the grains contain relatively large pores as those shown in Figure 4. Comparatively, the $\mathrm{FeCr}_{20} \mathrm{Ni}_{10}$ surface is the most heterogeneous among all three nitrided substrates. Some grains are very smooth and deeper and contain large pores (see arrow marks and Figure 4) thus reminding of the $\mathrm{NiCr}_{20}$ grains, whereas some other grains resemble more the nitrided pure Ni by underlining the slipping bands, hence being rougher (see height profile). A common feature observed on the three alloys is the occurrence of twinning within the grains, but again the morphology of twins differs from one matrix to the other as shown on Figure 5. In nitrided nickel [Figure 5 (a)] the twin seems to modify the sputtering behaviour thus giving rise to a different surface morphology on both sides of the twin. Conversely, in the iron-rich matrix [Figure 5 (b)], the twin has been fully peeled off giving rise to an even morphology of the grain. 


\subsection{Microhardness measurements}

The Vickers microhardness values shown in Figure 6 have been averaged from 10 indentations on each specimen surface. From one set of measurements to the other, the applied load was increased, which allows to plot the estimated indentation depth in the abscissa. In pure Ni [Figure 6 (a)], both the untreated and nitrided specimens follow the same hardness trend, in which the uppermost surface layers are harder than the innermost ones and it is typically associated to the plastic deformation induced upon mechanical polishing of the samples. However, careful inspection of the hardness values indicates that implantation has brought about a slight superficial hardening (around 12\%), which might be related the deformation induced upon implantation, hence inducing plastic deformation of the near surface region. It is also interesting to remark that after the nitridation process, an overall softening of the whole matrix occurs compared to raw $\mathrm{Ni}$ as assessed by the displacement to the right of the indentation depth and which may arise from metallurgical recovery at the implantation temperature.

After implantation of the $\mathrm{NiCr}_{20}$ substrates [Figure 6 (b)], a significant difference of hardness of the extreme surface (about 20\%) is readily observable up to about $2 \mu \mathrm{m}$, from which the same hardness values are found for both untreated and nitrided specimens. Again, in this sample hardening could have been produced by plastic deformation during mechanical polishing. However, since the procedure was the same for $\mathrm{Ni}$ and $\mathrm{NiCr}_{20}$, the hardness increase can be attributed to solid solution hardening $\left(\gamma_{\mathrm{N}}\right.$ phase formation).

Comparatively, the major hardness increase after nitridation is observed for the $\mathrm{FeCr}_{20} \mathrm{Ni}_{10}$ matrix. Indeed, for the shallowest indentation depths (about $1.5 \mu \mathrm{m}$ ) the implanted near surface region is about 4 times harder than the unimplanted one. Thereafter, hardness progressively decreases towards the values of the untreated steel matrix, which hardness is relatively higher than that of $\mathrm{Ni}$ and $\mathrm{NiCr}_{20}$.

\section{3.- Thermodynamic analyses}


Thermodynamic calculations have been carried out with the HSC software [11] taking into account the major compositions of the substrates, i.e. $\mathrm{Fe}$, $\mathrm{Ni}$ and $\mathrm{Cr}$, the atmospheric pressure and $10^{-2} \mathrm{~Pa}$ (implantation conditions) and by implanting the major charged $\mathrm{N}_{2}{ }^{+}$(g) species and alternatively, the uncharged $\mathrm{N}_{2}$ (g). Regardless of the approximation, all the calculations indicate that no nickel nitride forms at least from a thermodynamic point of view. On the contrary, chromium and iron nitrides may form as shown in Figure 7 for the evolution of the free energy of formation with temperature. The Cr-N reactions are exothermic $(\Delta H<0)$ and spontaneous $(\Delta G<0)$, especially when the uncharged $\mathrm{N}_{2}$ (g) is reacting with Cr. [Figure 7 (a)]. In addition, spontaneity increases with increasing temperature. Conversely, all Fe-N reactions are only slightly exothermic. In the steel matrix only the reaction in which $\mathrm{N}_{2}{ }^{+}(\mathrm{g})$ is involved seems to be spontaneous [Figure 7 (b)] but no significant variation of spontaneity occurs with increasing temperature contrary to the $\mathrm{NiCr}_{20}$ matrix.

The evolution of metal nitride formation in $\mathrm{NiCr}_{20}$ and in $\mathrm{FeCr}_{20} \mathrm{Ni}_{10}$ per mole of $\mathrm{N}_{2}{ }^{+}$(g) with increasing temperature is depicted in Figure 8. Regardless of the Cr-containing matrix, chromium nitrides formation [Figure 8 (a)] is enhanced with respect that of iron

nitrides [Figure 8 (b)]. Among the former, CrN formation decreases with increasing temperature whereas the amount of $\mathrm{Cr}_{2} \mathrm{~N}$ increases. Therefore, it can be deduced from Figure 8 (a) that $\mathrm{CrN}$ will be more prone to occur than $\mathrm{Cr}_{2} \mathrm{~N}$ at the implantation temperature of the stainless steel $\left(410^{\circ} \mathrm{C}\right)$. On the contrary, at $450^{\circ} \mathrm{C}$ (nitridation temperature of $\mathrm{NiCr}_{20}$ ) the thermodynamic amounts of both chromium nitrides do not significantly differ and thus, competition reactions may occur at the near surface of the $\mathrm{NiCr}_{20}$ matrix.

\section{4.- Discussion}

Nitridation by implantation-diffusion of the three fcc substrates (pure $\mathrm{Ni}, \mathrm{NiCr}_{20}$ and $\mathrm{FeCr}_{20} \mathrm{Ni}_{10}$ ) brings about quite different results in agreement with Williamson et al. [8]. As implantation was carried out under similar experimental conditions and the three metallic substrates possess face-centred cubic structures and relative similar grain size, it can be suggested that a chemical effect might be responsible to some extent for the observed differences. Therefore, nitridation in each substrate will be discussed 
separately. Only the effect of the major elements will be considered as some minor role of carbon atoms has been previously highlighted [e.g. 13,16].

\section{1.- Nitridation in pure nickel}

It has been shown by conventional $\theta-2 \theta$ X-ray diffraction (Figure 1a) that no extra peak appears as a result of the formation of a new phase compared to the untreated Ni matrix. This observation is supported by the HSC thermodynamic analyses and with the fact that no binary phase diagram exists in the literature [14] but is in contrast to previous results in which the appearance of the (102) peak of hexagonal $\mathrm{Ni}_{3} \mathrm{~N}$ and retention of about 0.4 at $\% \mathrm{~N}$ in the $\gamma$ phase were reported using $700 \mathrm{eV}$ and a higher flux $\left(2 \mathrm{~mA} \cdot \mathrm{cm}^{-}\right.$ ${ }^{2}$ ) at $400^{\circ} \mathrm{C}$ for $15 \mathrm{~min}$ [8]. Such nitrogen content obviously falls within the detection limit of the EDS technique employed in this present study, but can be considered as negligible. Therefore, the roles of energy and ion flux are of ground importance as thoroughly discussed by Wei [15] and more recently by Abrasonis [13,16,17]. Sputtering of the surface is also accompanied by an increase in surface roughness (Figure 3), which value varies from grain to grain (150-275 $\AA$ ) and probably induces twinning (Figure 5). Moreover, a high number of pores appear on the surface of the nitrided specimens (Figure 2). Indeed, incorporation of nitrogen in nickel has been reported to occur by ion implantation as far as the temperature of $375^{\circ} \mathrm{C}$ is not surpassed [18] because otherwise nitrogen will be released due to its low solubility in $\mathrm{Ni}$ [19]. According to the work of Pranevicius et al. [20] on a fcc AISI 304L stainless steel, the surface roughness can be derived from the competition between surface kinetics and bulk diffusion. Nucleation of roughness would first occur by relocation of adatoms, formation of surface vacancies and removal of atoms, which in turn lead to the appearance of clusters of atoms in other regions of the surface. The development of surface roughness subsequently occurs by further relocation and sputtering of atoms displaced by the ion beam. Thereafter, diffusion of nitrogen seems to occur mainly along grain and sub-grain boundaries creating compressive stresses [21]. In nickel, the metastable incorporation of nitrogen can in fact occur by two paths: through the grains and along the grain boundaries. In the former, nitrogen atoms are forced to diffuse inwardly because of the low energy - high flux implantation process. Within the metallic substrate, atomic nitrogen can then recombine as molecular nitrogen, thus 
raising locally the pressure and inducing plastic deformation of nickel. As a result, a blistered surface appears (Figure 2). Due to the recession of the metal surface upon implantation, the blisters are peeled off and the pores are then visible. Since the solubility of nitrogen in nickel is very low the observed porosity is rather shallow. The larger number of pores and blisters are however found at the grain and twin boundaries rather than within the grains as also inferred in a previous study [22]. This seems to support the idea that diffusion of nitrogen might be more prone to occur along these short circuit paths, which also become readily saturated in nitrogen thus inducing significant plastic deformation all around.

A likely explanation to the highly anisotropic surface roughness in nickel may be related to the sputtering and nitrogen penetration. Indeed, it is widely accepted that sputtering may randomly occur depending on the incoming ion flow but also on the response of the substrate. As the binding energy is different for each grain, a different sputtering rate can then be expected. Likewise, the ions will lose more energy in collisions if striking against close packed planes compared to less compact planes. Therefore, electron backscattered diffraction measurements should be carried out to correlate grain orientation to roughness.

\section{2.- Nitridation in $\mathrm{NiCr}_{20}$}

In contrast to pure nickel, $\mathrm{NiCr}_{20}$ is able to retain up to about 10 at $\% \mathrm{~N}$ on average as revealed by EDS microanalyses. The XRD patterns (Figure 1b) clearly depict the formation of the so-called expanded austenite, i.e. an fcc phase with nitrogen in solid solution [15]. From these XRD patterns no chromium nitride formation has been observed even though decomposition of the $\gamma_{\mathrm{N}}$ phase at $450^{\circ} \mathrm{C}$ has been quoted to produce $\mathrm{Ni}$ and metal nitrides in $\mathrm{NiCr}_{20}$ [23] and in Inconel $690\left(\mathrm{NiCr}_{30} \mathrm{Fe}_{10}\right)$ [24]. As inferred in Table 2, the expansion of the (200) planes is twice that of the remaining planes. Previous studies on plasma nitriding of Inconel 690 [24,25] also showed a larger width of the (200) peaks compared to the other reflections but disagreed with the idea of different N contents for (200) and (111) suggested by Ozturk and Williamson [26]. Conversely, the explanation of such feature has been put forward in terms of the likely anisotropy of stress on strain, plastic deformation of the nitrided layer and the possible 
incidence of oxygen in each crystallographic plane. The latter factor could in principle be rejected in our study because of the $\mathrm{Ar}^{+}$cleaning treatment carried out prior to nitridation [16].More recently, it has been suggested that the faster nitriding rate in the grains that contribute to the (200) reflection could adequately be explained by the formation of stacking faults together with the stress generated thus bring about the anomalous expansion of the (200) planes [12].

As discussed above for $\mathrm{Ni}$, roughness can result from ion induced atomic processes on the surface and plastic deformation. However, roughness in $\mathrm{NiCr}_{20}$ is the lowest among the three implanted materials (see Figure 3). In fact, only from thermodynamic considerations (Figures 7 and 8) when implanting either $\mathrm{N}_{2}$ (g) or $\mathrm{N}_{2}{ }^{+}$(g) chromium shows a strong tendency to form either the fcc $\operatorname{CrN}\left(\Delta \mathrm{H}^{\circ}=-40 \mathrm{~kJ} \cdot \mathrm{mol}^{-1}\right)$ or the hcp $\mathrm{Cr}_{2} \mathrm{~N}$ $\left(\Delta \mathrm{H}^{\mathrm{o}}=-38 \mathrm{~kJ} \cdot \mathrm{mol}^{-1}\right)$ phases, which have not been observed experimentally. However, this may indicate that $\mathrm{Cr}$ can significantly increase $\mathrm{N}$ solubility in $\mathrm{Ni}$. On the other hand, Rivière and co-workers [27] already indicated that although preferential bonding occurred between $\mathrm{N}$ and $\mathrm{Cr}$, no defined nitride formed in a $\mathrm{FeCr}_{20} \mathrm{Ni}_{10}$ substrate and concluded that Cr played a specific role in the atomic transport of nitrogen [28], rather in agreement with the trapping-detrapping mechanism proposed by Möller et al. [29]. This means that most of nitrogen arriving at the surface can remain in the matrix due to enhanced solubility, diffuse inwardly and be trapped at chromium atoms. However, at the implantation temperature $\left(450^{\circ} \mathrm{C}\right)$ chromium may also diffuse outwardly $[2,15]$ and preferentially interact with nitrogen thus developing less porosity than in pure $\mathrm{Ni}$, where the excess nitrogen tends to form bubbles [30]. Incorporation of nitrogen would then lead to swelling of the grains due to a faster nitriding rate in the (200) oriented grains [12] and plastic deformation of the fcc lattice [31].

\section{3.- Nitridation in $\mathrm{FeCr}_{20} \mathrm{Ni}_{10}$}

Using similar experimental conditions as for pure $\mathrm{Ni}$ and $\mathrm{NiCr}_{20}$, the Fe-base alloy mainly develops the expanded austenite $\left(\gamma_{N}\right)$ phase on its surface (Figure 1c). The approach of Vegard's law for substitutional solid solutions indicates that more nitrogen has been retained compared to $\mathrm{NiCr}_{20}$ (Table 2) but its distribution is also highly anisotropic and follows the same trend as for $\mathrm{NiCr}_{20}$, i.e. more lattice expansion seems 
to occur for the grains reflecting the (200) planes. Therefore, assuming homogeneous distribution of chromium in both matrices, it can be deduced that anisotropy only arises from mechanical effects. Indeed, by comparing single crystal and polycrystalline steel substrates it has been recently suggested $[12,16]$ that as nitrogen is incorporated to the fcc matrix, compressive stresses are generated that lead to distortions, plastic deformation and even lattice rotations in an anisotropic fashion because the $\{001\}$ planes have less slip systems than other planes [31]. As a result of the anisotropic deformation, heterogeneous diffusion will occur thus modifying the nitrogen ingress rate [12].

Furthermore, the $\mathrm{FeCr}_{20} \mathrm{Ni}_{10}$ develops the roughest surface among the three studied substrates (Figures 2 and 3), but a small number of relatively deep pores. As previously mentioned, surface roughness can originate from ion induced atomic processes on the surface and plastic deformation by misfit dislocation glide as nitrogen is incorporated into the matrix [21]. However, the differences in surface roughness between both chromium containing substrates are rather significant. In pure $\mathrm{Ni}$, roughness development is enhanced because the nickel atoms reject nitrogen, which is inconsistent with the fact that $\mathrm{NiCr}_{20}(80 \mathrm{at} \% \mathrm{Ni})$ has in general a smoother surface than $\mathrm{FeCr}_{20} \mathrm{Ni}_{10}$ (10 at\% Ni). Therefore, chemical interactions between nitrogen and the metallic atoms can help in explaining such phenomenon.

Indeed, $\mathrm{FeCr}_{20} \mathrm{Ni}_{10}$ and $\mathrm{NiCr}_{20}$ incorporate different amounts of nitrogen. Möller et al. [29] suggested a mechanism in which nitrogen atoms would diffuse inwardly to form new bonds with chromium atoms in progressively deeper atomic layers. Since the chromium content is the same in both matrices, nickel and iron may be responsible for the observed differences. On the one hand, because nickel rejects nitrogen, the nickelrich substrate $\left(\mathrm{NiCr}_{20}\right)$ incorporates less nitrogen. On the other hand, from a thermodynamic point of view the free enthalpy $(\Delta G)$ is more negative (thus, more spontaneous reaction) upon the formation of chromium nitrides than that of iron nitrides (Figures 7). However, the iron effect cannot be neglected if the chemical potential of the species is also taken into account; i.e. when one mole of nitrogen encounters the substrate surface $70 \%$ of the atoms are composed of iron and only $20 \%$ of chromium. 
As a result, iron can also enhance incorporation of nitrogen at least to some extent. Indeed, Rivière et al. [27] found by X-ray photoelectron experiments that nitrogen was always detected in a nitride type state and that it was preferentially bound to chromium, without specific nitride formation. Similarly, a small amount of iron atoms showed the same nitride type bonding but only at the outermost surface. Therefore, iron interaction together with a lower nickel content (which rejects nitrogen) results in higher nitrogen supersaturation in the superficial layers of $\mathrm{FeCr}_{20} \mathrm{Ni}_{10}$ than in $\mathrm{NiCr}_{20}$. Thereafter, because of the difference in chemical potentials between the external layer and the bulk, diffusion will be enhanced. As a result, the Fe-based alloy, which incorporates more nitrogen will exhibit a higher degree of deformation. This induces significant swelling of the grains, thus developing rougher surfaces. Due to the nitrogen contents retained in the Fe-based alloy (up to 17 at\%), a mixed $\gamma_{N}+\gamma$ region probably develops at the outermost surface and the resulting hardness (12 GPa, cf. Figure 6) is lower than the 20$22 \mathrm{GPa}$ reported in the literature for a high nitrogen containing $\gamma_{\mathrm{N}}$ phases [8].

\section{5.- Conclusion}

Similar low energy, high flux nitridation processing conditions on different fcc metallic substrates lead to very different results depending on the chemical composition of the matrix. It has been shown that pure nickel does not develop an expanded austenite phase due to rejection of nitrogen. The tiny retained amount of nitrogen creates blisters and pores as nitrogen tries to be triggered off the substrate. The major surface roughness is then developed by sputtering. On the contrary, once chromium is added, a expanded austenite phase develops but nitrogen uptake is still limited by nickel rejection. In turn, iron atoms can thermodynamically favour nitrogen uptake at least at the outermost surface. The higher the nitrogen intake, the higher the degree of deformation including and grain swelling, which leads to rougher and harder surfaces.

\section{6.- References}

1. A.M. Jones, S.J. Bull, Surf. Coatings Technol. 83 (1996) 269.

2. R. Wei, J.J. Vajo, P.J. Wilbur, J.A. Davis, D.L. Williamson, G.A. Collins, Surf. Coat. Technol. 83 (1996) 235. 
3. D.L. Williamson, J.A. Davis, P.J. Wilbur, J.J. Vajo, R. Wei, J.N. Matosian, Nucl. Instrum. Methods, Phys. Res. B 127/128 (1997) 930.

4. J.P. Rivière, C. Brin, Ph. Méheust, J.P. Villain, R. Cauvin, J. Phys IV 11 (2001) 71 (in French).

5. J.P. Rivière, P. Méheust, J.P. Villain, Surf. Coatings Technol. 158-159 (2002) 647.

6. S. Picard, J.B. Memet, R. Sabot, J.L. Grosseau-Poussard, J.P. Rivière, R. Meilland, Mat. Sci. Eng. A303 (2001) 163.

7. Z.L. Zhang, T. Bell, Surf. Eng. 1 (1985) 131.

8. D. Williamson, J.A. Davis, P.J. Wilbur, Surf. Coatings Technol. 103-104 (1998) 178.

9. J.P. Rivière, P. Méheust, J.A. García, R. Martínez, R. Sánchez, R. Rodríguez, Surf. Coatings Technol. 158-159 (2002) 295.

10. Y. Ando, S. Tobe, H. Tahara, T. Yoshikawa, Vacuum 65 (2002) 403.

11. Outokompu HSC Chemistry for Windows, Outokompu Research Oy, Pori, 1994.

12. G. Abrasonis, J.P. Rivière, C. Templier, A. Déclemy, L. Pranevicious, X. Milhet J. Appl. Phys. 97 (8) (2005) 3531.

13. G. Abrasonis, J.P. Rivière, C. Templier, L. Pranevicius, N.P. Barradas, J. Appl. Phys. 97 (12) (2005) 4906.

14. Smithells Metals Reference Book, $6^{\text {th }}$ Ed. Eric A. Brandes, Butterworths \& Co. Publishers, London (1983).

15. R. Wei, Surf. Coatings Technol. 83 (1996) 218.

16. G. Abrasonis, PhD Thesis, University of Poitiers, France, 2003.

17. G. Abrasonis, J.P. Rivière, C. Templier, S. Muzard, L. Pranevicius, Surf. Coatings Technol. 196 (2005) 279.

18. K. Han, D.H. Fairbrother, Appl. Surf. Sci. 195 (2002) 229.

19. M. Hansen, K. Anderko, Constitution of Binary Alloys $2^{\text {nd }}$ Ed. McGraw-Hill Co. Inc., New York (1958), p. 984.

20. L. Pranevicius, C. Templier, J.P. Rivière, P. Méheust, L.L. Pranevicius, G. Abrasonis, Surf. Coatings Technol. 135 (2001) 250.

21. L. Pranevicius, L.L. Pranevicius, D. Milcius, S. Muzard, C. Templier, J.P. Rivière, Vacuum 72 (2004) 161. 
22. F. Pedraza, M. Reffass, G. Abrasonis, C. Savall, J.P. Rivière, Surf. Coatings Technol. 176 (2004) 236.

23. F. Regent, J. Musil, Surf. Coatings Technol. 142-144 (2001) 146.

24. H. He, T. Czerwiec, C. Dong, H. Michel, Surf. Coatings Technol. 163-164 (2003) 331.

25. T. Czerwiec, H. He, A. Saker, L. Tran Huu, C. Dong, C. Frantz, H. Michel, Surf. Coatings Technol. 174-175 (2003) 131.

26. O. Ozturk, D.L. Williamson, J. Appl. Phys. 77 (8) (1995) 3839.

27. J.P. Rivière, M. Cahoreau, P. Meheust, J. Appl. Phys. 91 (10) (2002) 6361.

28. J.P. Rivière, P. Meheust, J.P. Villain, C. Templier, M. Cahoreau, G. Abrasonis, L. Pranevicius, Surf. Coatings Technol. 158-159 (2002) 99.

29. W. Möller, S. Parascandola, T. Telbizova, R. Günzel, E. Richter, Surf. Coatings Technol. 136 (2001) 73.

30. F. Pedraza, J.L. Grosseau-Poussard, G. Abrasonis, J.P. Rivière, J.F. Dinhut, J. Appl. Phys. 94 (12) (2003) 7509.

31. B. Clausen, T. Lorentzen, M.A.M. Bourke, M.R. Daymond, Mat. Sci. Eng. A259 (1999) 17. 


\section{List of tables}

Table 1. Substrates major composition (at\%), and the corresponding maximum temperatures achieved upon nitridation.

\begin{tabular}{|l|c|c|c|c|}
\hline substrate & $\mathrm{Fe}$ & $\mathrm{Cr}$ & $\mathrm{Ni}$ & $\mathrm{T}\left({ }^{\circ} \mathrm{C}\right)$ \\
\hline $\mathrm{FeCr}_{20} \mathrm{Ni}_{10}$ & 70 & 20 & 10 & 410 \\
\hline $\mathrm{NiCr}_{20}$ & - & 20 & 80 & 450 \\
\hline $\mathrm{Ni}$ & - & - & $\sim 100$ & 470 \\
\hline
\end{tabular}

Table 2. Lattice parameters of the $\mathrm{N}$-containing $\gamma_{\mathrm{N}}$ and $\mathrm{N}$-free $\gamma$ austenite phases, the relative expansion induced, an their corresponding average atomic nitrogen contents, $\mathrm{C}_{\mathrm{N}}$, as a function of the diffraction plane (hkl) in $\mathrm{NiCr}_{20}$ and $\mathrm{FeCr}_{20} \mathrm{Ni}_{10}$ substrates.

\begin{tabular}{|c|c|c|c|c|c|}
\hline & hkl & 111 & 200 & 220 & 311 \\
\hline \multirow{4}{*}{$\mathrm{NiCr}_{20}$} & $\mathbf{a}_{\gamma \mathrm{N}}, \mathbf{n m}$ & 0.3580 & 0.3637 & 0.3589 & 0.3612 \\
\hline & $\mathbf{a}_{\gamma}, \mathbf{n m}$ & 0.3538 & 0.3540 & 0.3545 & 0.3548 \\
\hline & expansion, \% & 1.2 & 2.8 & 1.2 & 1.8 \\
\hline & $\mathrm{C}_{\mathrm{N}}$, at $\%$ & $\sim 6$ & 13.5 & 6 & $\sim 9$ \\
\hline \multirow{4}{*}{$\mathrm{FeCr}_{20} \mathrm{Ni}_{10}$} & $\mathbf{a}_{\gamma \mathrm{N}}, \mathbf{n m}$ & 0.3666 & 0.3716 & 0.3666 & 0.3683 \\
\hline & $\mathbf{a}_{\gamma}, \mathbf{n m}$ & 0.3572 & 0.3583 & 0.3583 & 0.3583 \\
\hline & expansion, \% & 2.6 & 3.7 & 2.3 & 2.7 \\
\hline & $\mathrm{C}_{\mathrm{N}}, \mathrm{at} \%$ & 13 & 18.5 & 11.5 & 14 \\
\hline
\end{tabular}



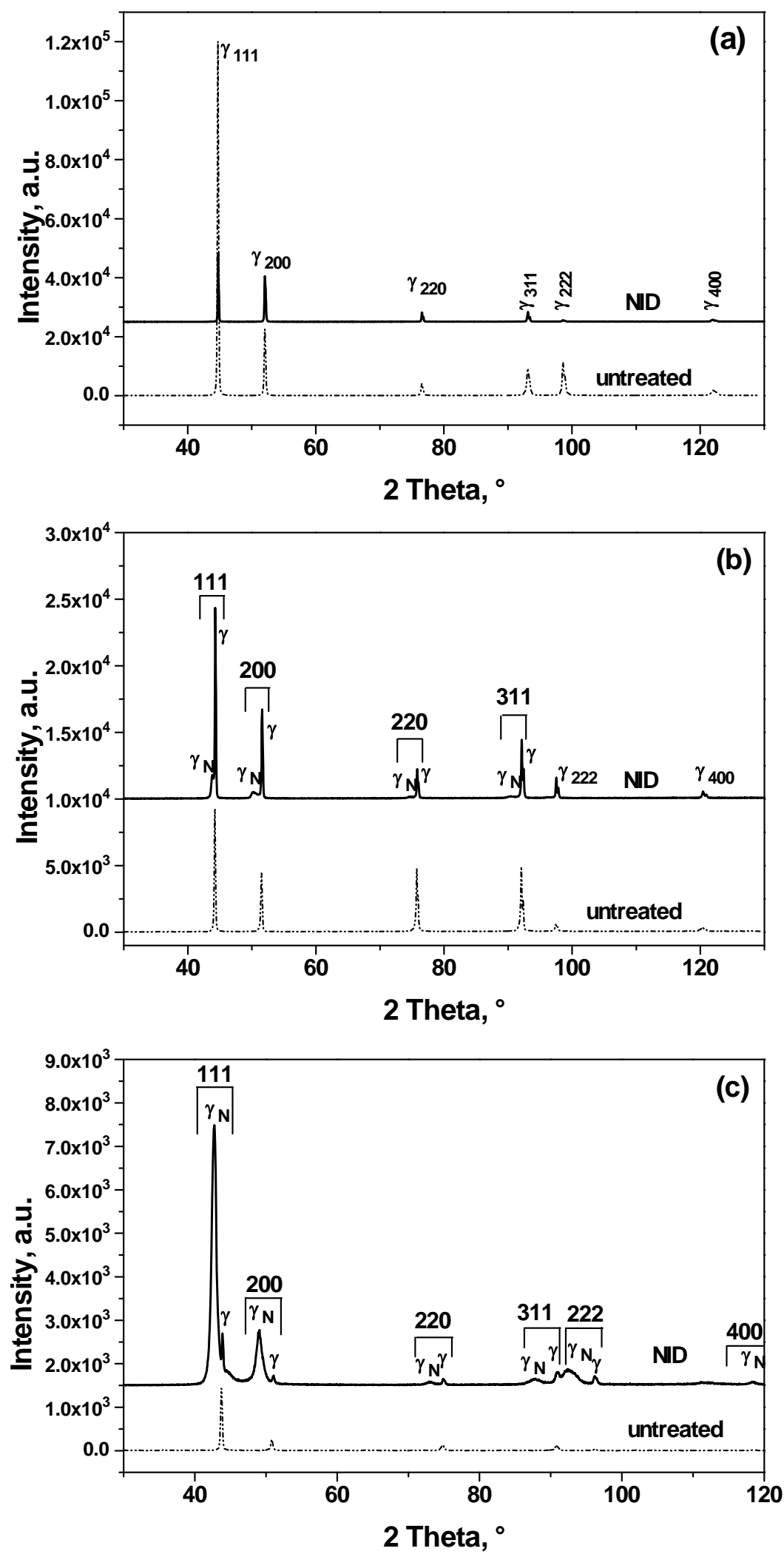

Figure 1.- X-ray diffraction patterns obtained in the Bragg-Brentano geometry of the raw materials (dashed lines) and nitrided (solid lines) by implantationdiffusion (NID) on (a) Ni (b) Ni20Cr and (c) Fe10Ni20Cr substrates. 


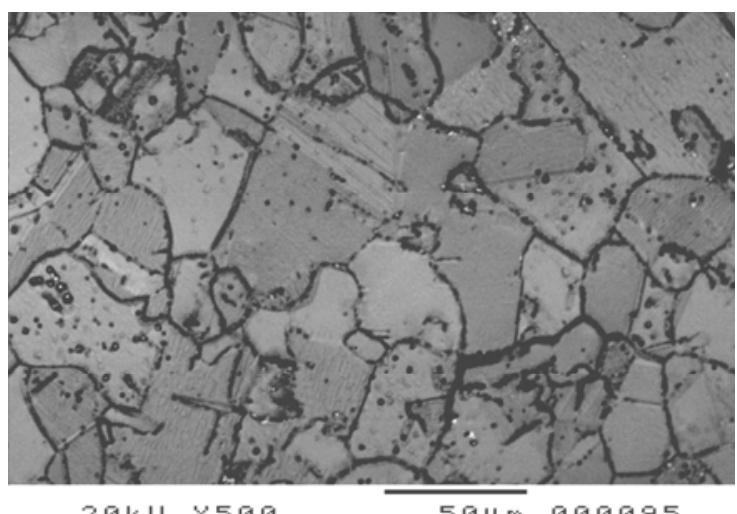

$20 \mathrm{kU} \times 500$
$59 \mu \mathrm{m}$ ดดดด95

(a)

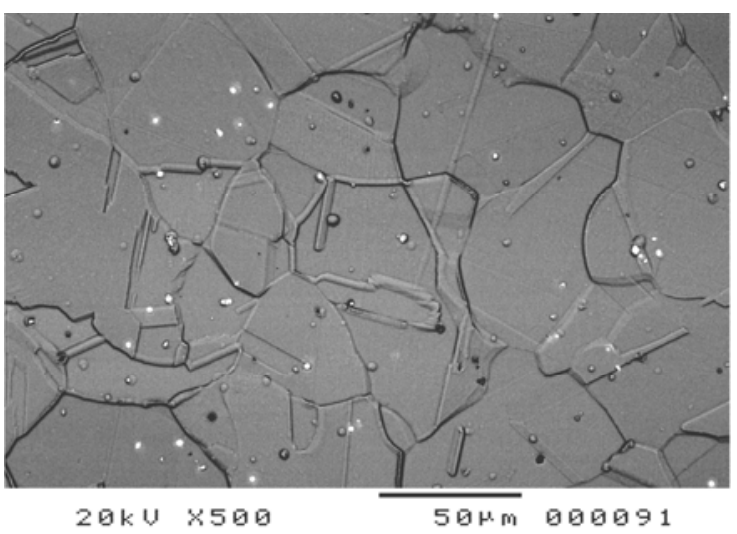

(b)

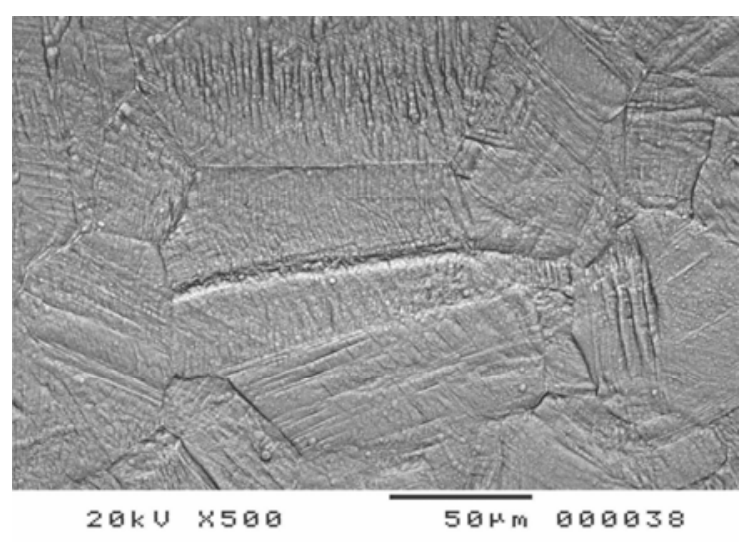

(c)

Figure 2.- SEM surface morphology of the different metallic substrates after nitridation showing extensive deformation and preferentially sputtered grains (a) $\mathrm{Ni}$, (b) Ni20Cr and (c) Fe20Cr $2010 \mathrm{Ni}$. 


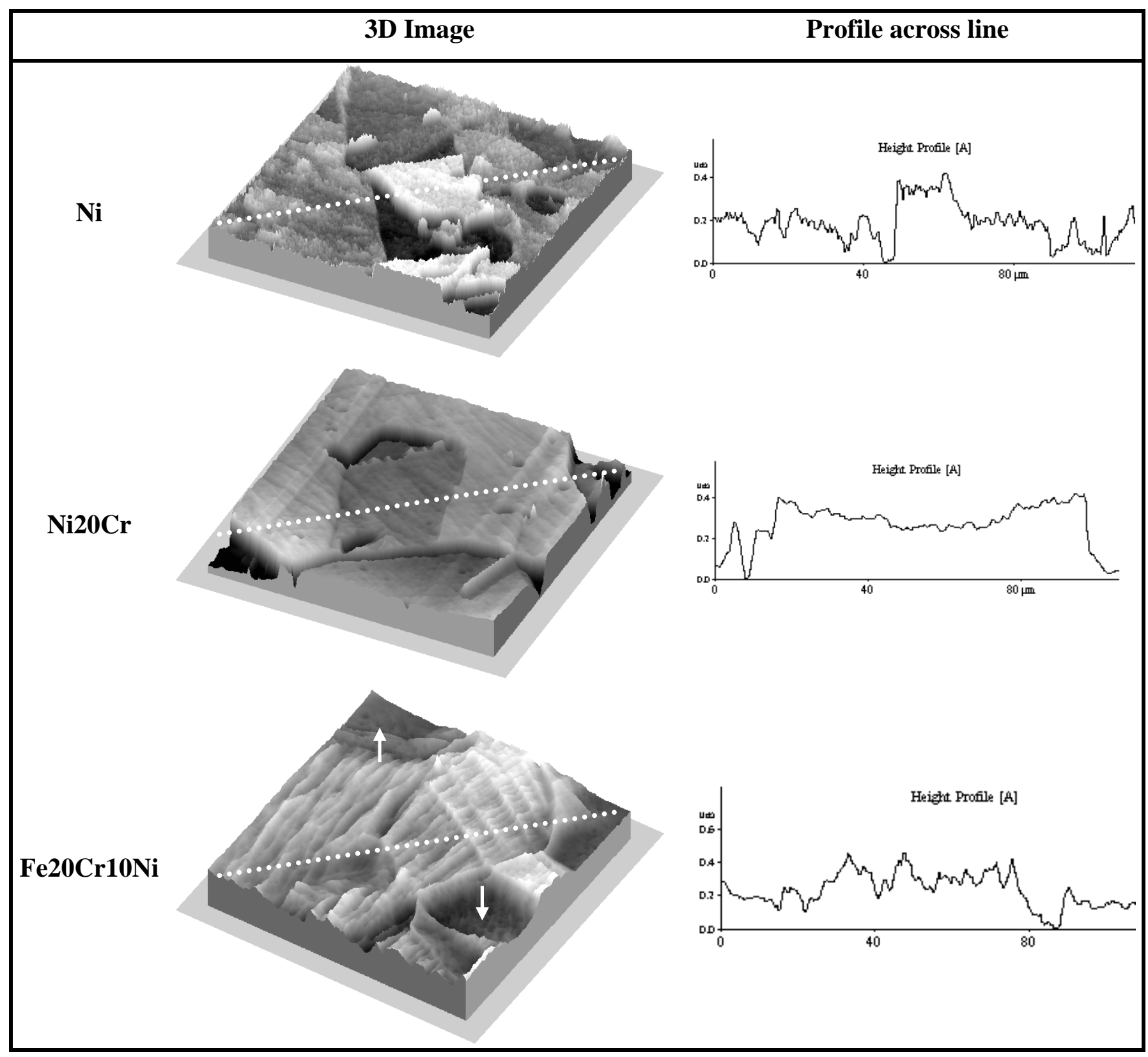

Figure 3.- 3D AFM images of the substrates after nitridation and their corresponding height profiles across the dot lines showing significant anisotropy in Ni (top), Ni20Cr (middle) Fe20Cr10Ni (bottom). 


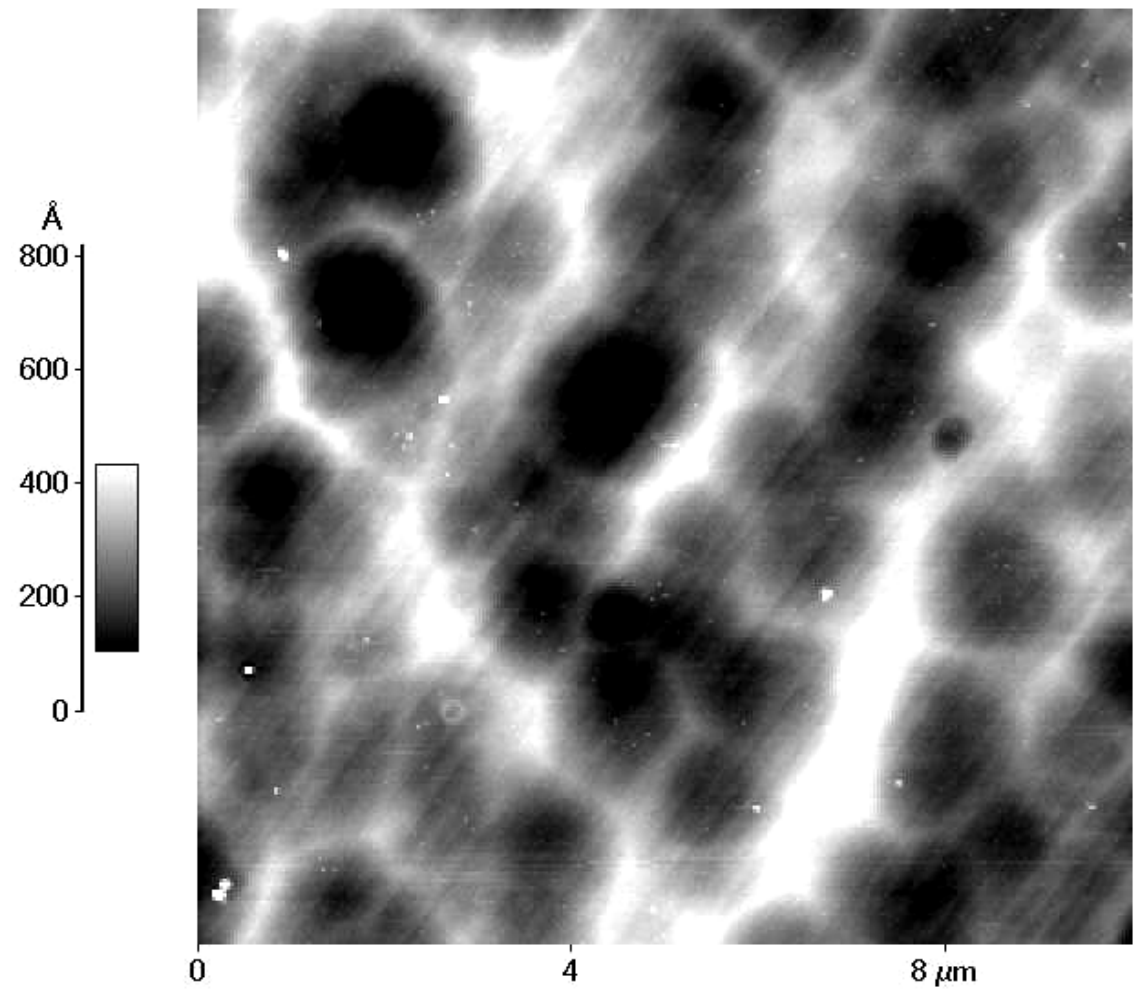

Figure 4.- AFM image (10x10 $\mu \mathrm{m}$ area) showing the round morphology of the porosity found in the Cr-bearing alloys. 

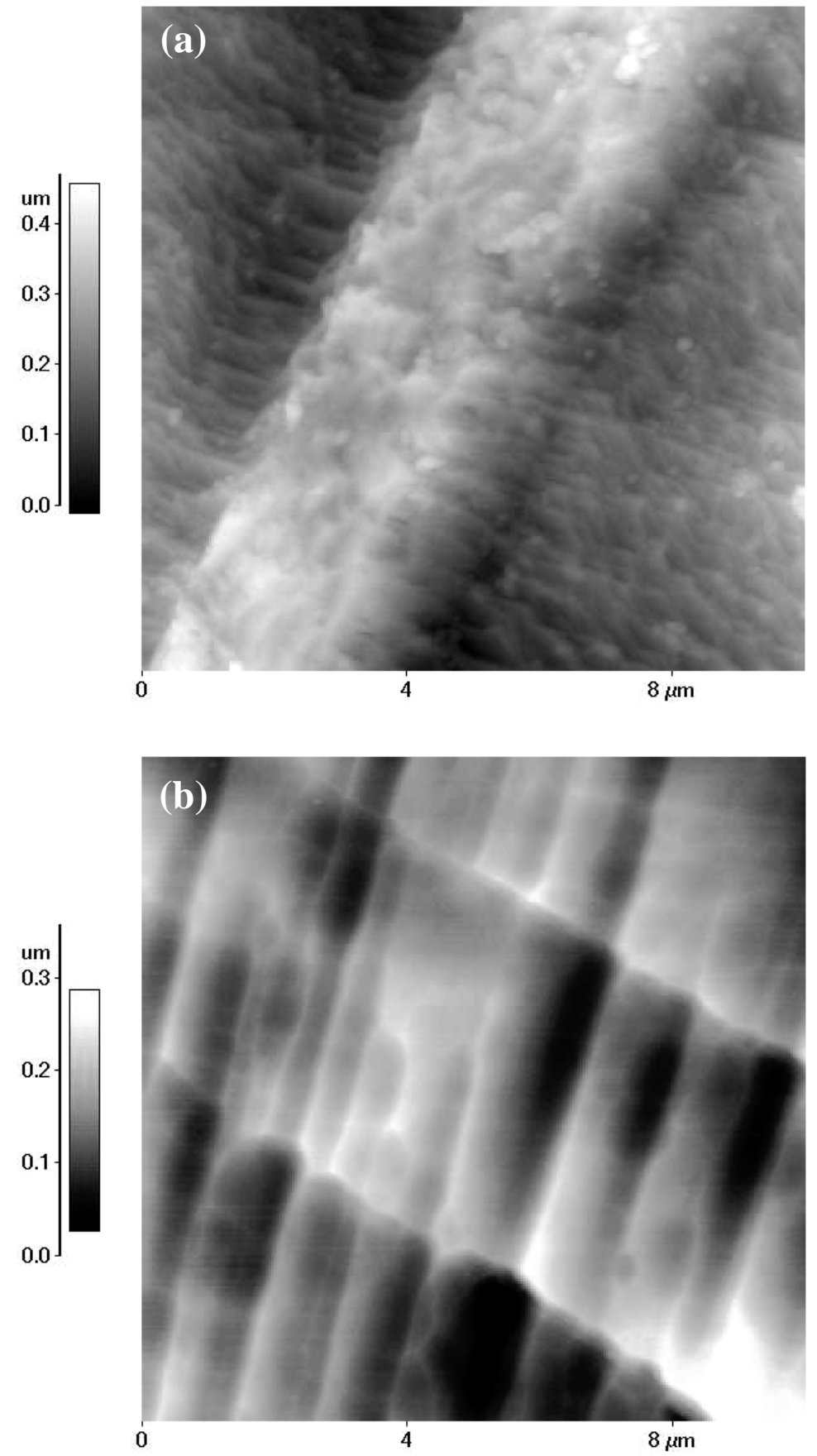

Figure 5.- AFM images (10x10 $\mu \mathrm{m}$ areas) showing the different morphology of the twins developed after nitridation in (a) pure Ni and (b) Fe20Cr10Ni. 

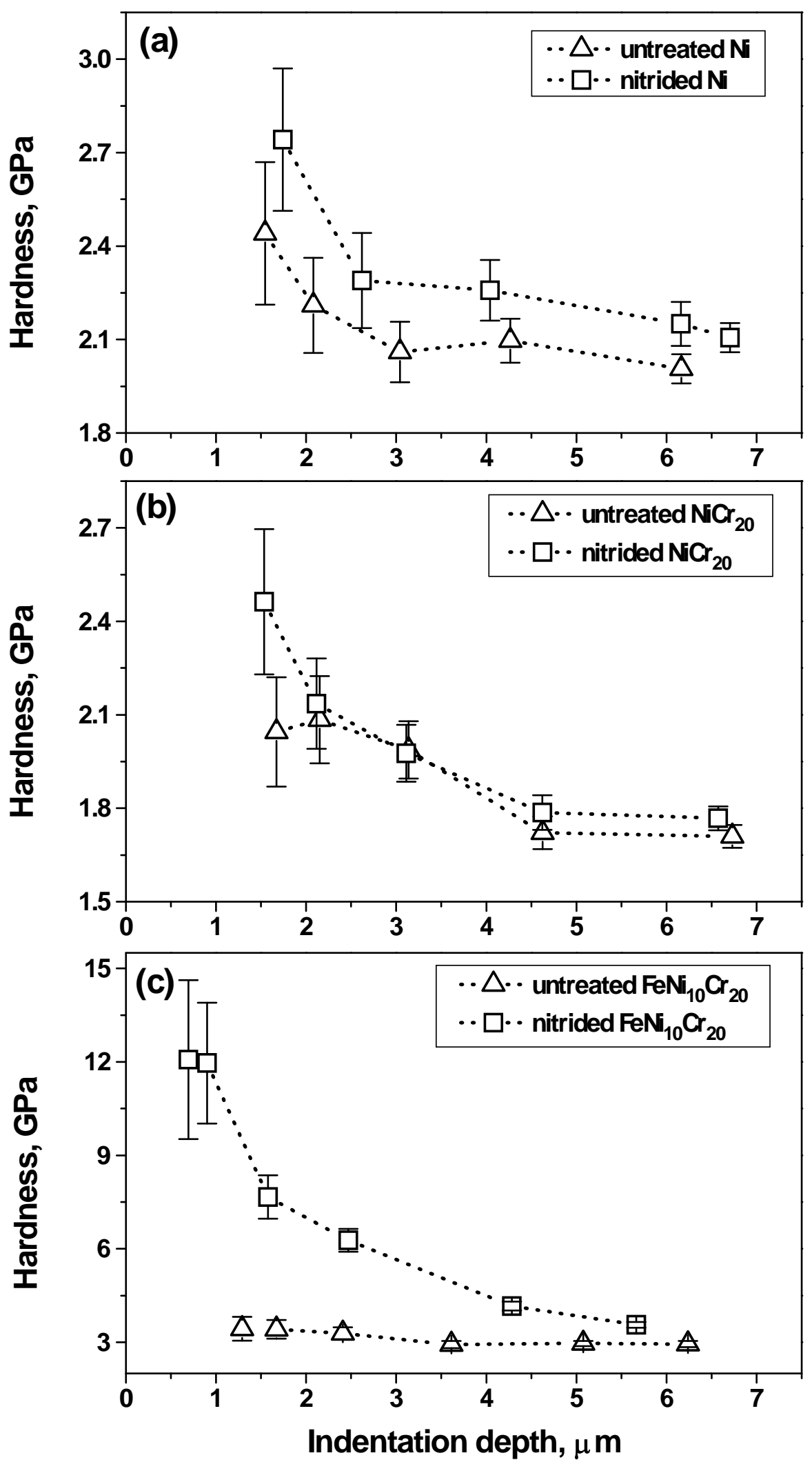

Figure 6.- Vickers microhardness values vs. indentation depth derived from the different loads imposed for the untreated (triangles) and nitrided (squares) (a) $\mathrm{Ni}$ and (b) Ni20Cr and (c) Fe20Cr10Ni substrates. 

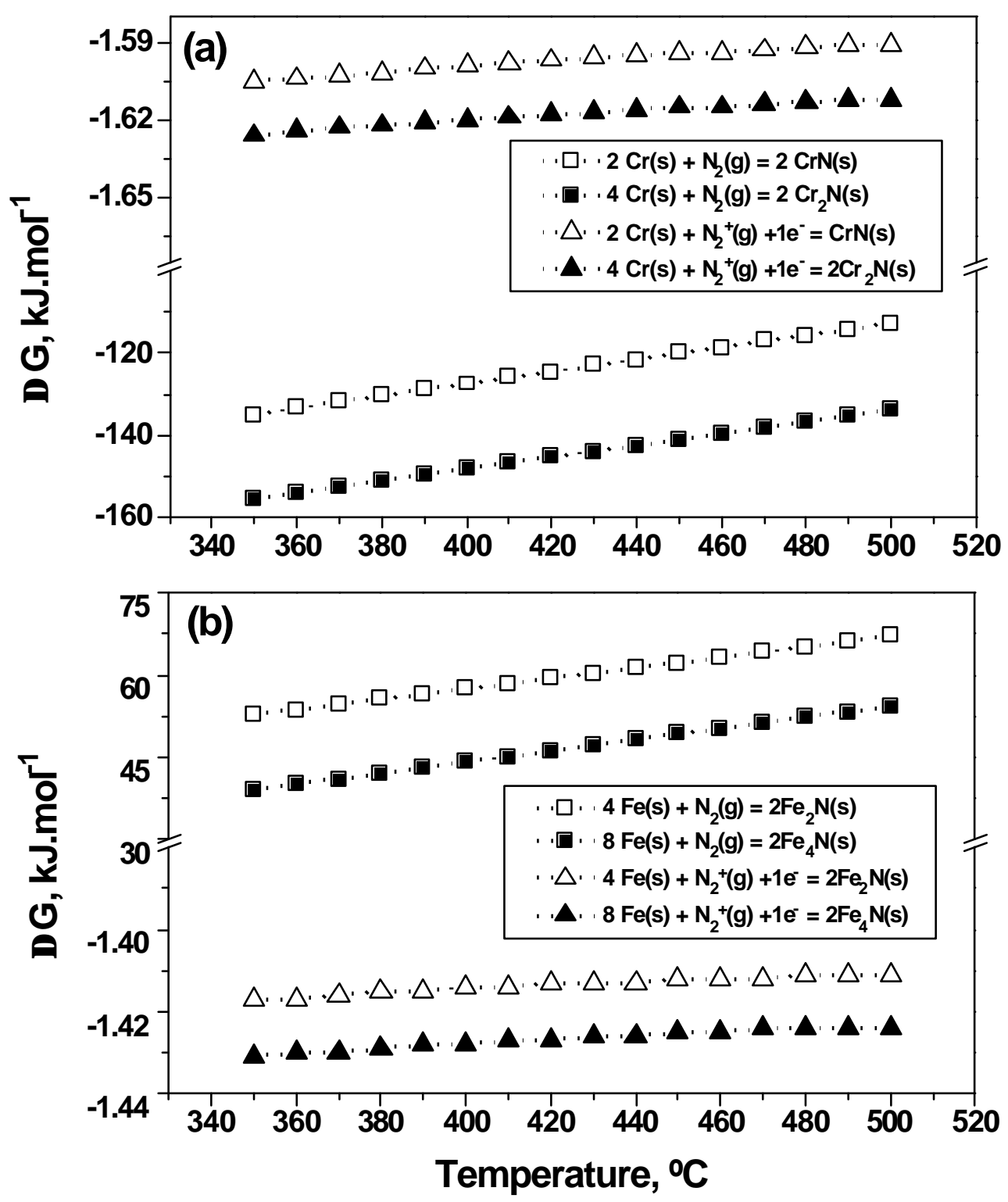

Figure 7.- Evolution of the Gibbs free energy of (a) chromium nitrides and (b) iron nitrides with temperature at $10^{-2} \mathrm{~Pa}$ according to HSC thermodynamics calculations [11]. 

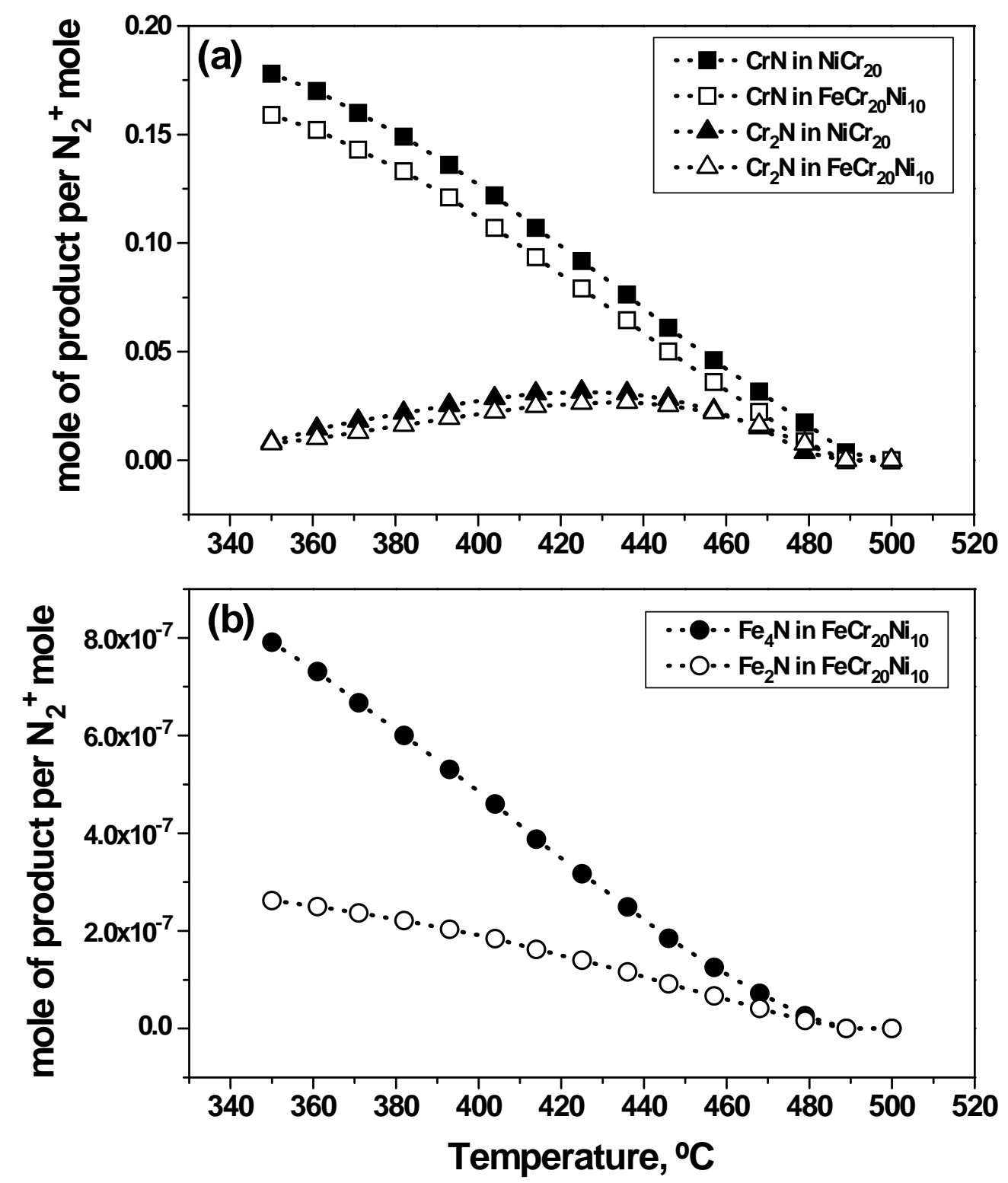

Figure 8.- Evolution of mole of metal nitride produced per mole of $\mathrm{N}_{2}^{+}(\mathrm{g})$ as a function of temperature at $10^{-2}$ Pa according to the HSC thermochemical calculations [11] (a) chromium nitrides formation in both $\mathrm{Cr}$-containing substrates and (b) iron nitrides in the Fe-containing matrix. 